\title{
Hydrological dispersion module of JRODOS: development and pilot implementation - the vistula river basin
}

\author{
M. ZHELEZNYAK ${ }^{1}$, S. POTEMPSKI ${ }^{2}$, R. BEZHENAR $^{1}$, A. BOYKO ${ }^{1}$, I. IEVDIN ${ }^{1}$, \\ A. KADLUBOWSKI ${ }^{3}$, D. TRYBUSHNYI ${ }^{1,4}$
}

\begin{abstract}
Contemporary open source JAVA technologies implemented within the EURANOS project for the cross-platform re-engineering of the decision support system RODOS (JRODOS) were used also to redesign the Hydrological Dispersion Module (HDM) of this system. JHDM - the hydrological model chain of JRODOS contains models to simulate the radionuclide transport in the system "atmospheric fallout on watershed - river net" and calculate the doses via aquatic pathways. JHDM used for this purpose a limited number of the input parameters to characterize the hydrological properties of the catchment/river network of interest. The pilot implementation of JHDM for the Vistula river basin carried out by POLATOM and supported by the national hydrological institute, demonstrated good perspectives of the approach used in JHDM for the decision support in cases of accidental contamination of water systems. Particular needs for further improvements of the JHDM software system have been identified.
\end{abstract}

\section{Introduction}

In close cooperation with RODOS Users Group (RUG), a cross-platform version of RODOS based on Java technologies has been developed (Ievdin et al., 2010) within the EURANOS project. The requirements expressed by the RUG emphasized that the development of the re-engineered RODOS should strengthen the weaknesses of the previous RODOS versions developed for HP UNIX platform: too complicated user interface, complex administration and adaptation to national conditions, limited applicability only in the software/hardware environment of HP PA-RISC architecture. These weaknesses were natively also part of the RODOS Hydrological Dispersion Module (HDM) that was developed in 1992-2003 (Zheleznyak et al., 2002; Raskob et al., 2004). This version of the HDM included a set of the models mainly developed and tested within Chernobyl

\footnotetext{
Ukrainian Center of Environmental and Water Projects, Prospect Glushkova, 42, 03187 Kiev, Ukraine. Institute of Atomic Energy POLATOM, Centre of Excellence MANHAZ, 05-400 Otwock-Swierk, Poland.

Institute of Meteorology and Water Management, Podleśna 61, 01-673 Warsaw, Poland.

Karlsruhe Institute of Technology, Kaiserstraße 12, 76131 Karlsruhe, Germany.
} 
related aquatic studies (Onishi et al., 2006) for simulation of the following processes:

- radionuclide washout from watersheds to a river network by rainfall generated runoff (box model RETRACE) (Kolomeev and Madsen, 2002);

- radionuclide transport in rivers in solute, attached to suspended sediments and in the in river bed, simulated on the basis of the pre-calculated flow and sediment dynamics in river networks (one-dimensional model RIVTOX) (Zheleznyak et al., 1993; Johannessen et al., 2010);

- radionuclide transport in river floodplains, shallow reservoirs, lakes and coastal areas in solute, attached to suspended sediments and in the bottom sediments simulated on the basis of the pre-calculated 2D flow and sediment concentrations fields (two-dimensional model COASTOX) (Zheleznyak et al., 1992; Monte et al., 2006);

- radionuclide transport in deep stratified lakes and reservoirs, estuaries based on the simulation of the 3D flow and the suspended sediments (3D model THREETOX) (Margvelashvili et al., 1997; Johannessen et al., 2010);

- radionuclide migration in the marine foodchain (box model POSEIDON) (Lepicard et al., 2004);

- internal and external doses exposed via aquatic foodchain and dose pathways (model FDMA) (Gering et al., 2003);

Customization of these models to a specific site required long-time manual processing of hydrological and river/marine hydraulics data, which usually is not available in the national nuclear emergency response centers. Integrating a set of the complicated models the RODOS-HDM required always the involvement of experts in hydrological/hydraulic modeling for the customization of HDM to national conditions. Furthermore, the usage was relatively complicated. These reasons were seen as the major obstacles related to an HDM implementation in national emergency centers.

\section{HDM re-enginering: objectives and models}

As part of the RODOS system re-engineering within the EURANOS project (Ievdin et al., 2010) a new version of the HDM module (JHDM) has been developed. The objectives of the HDM re-engineering were formulated as 1) development of user friendly software module using benefits of JAVA technologies elaborated for JRODOS (1) and 2) integration of only those models that describe the most important aquatic pathways. During the design of the JHDM, the former independently operating aquatic transport models have been combined to one model chain describing the sequence of the processes "atmospheric fallout to watershed" - "radionuclide inflow to river net" - 
"radionuclide transport in river" - "doses via aquatic exposure pathways". Further, these models were simplified to decrease the amount of input data to basic information which can be collected in each national emergency response center without involvement of significant recourses. The composition of the models in JHDM was initially tested within an EURANOS demonstration subproject as a "stand-alone" module for the Danube river basin. JHDM was then extended as a module for integration into JRODOS and this version was tested for the Vistula basin, Poland. The simulation models of JHDM, the user interface and the results of customization for the Vistula river are described in the following sections of the paper.

\subsection{J-RETRACE - model of radionuclide washout from watersheds}

J-RETRACE is a simplified version of the RETRACE model (Kolomeev and Madsen, 2002) based on the two main assumptions:

(a) the rate of the radionuclide wash off formed by each elementary grid cell of the watershed is linearly connected with the precipitation rate and the density of the fallout in this cell through the "wash-off" coefficient specific for each radionuclide;

(b) radionuclides washed out from the cell are transported without time delay to the nearest river channel cell, i.e. to the 1-D grid element of the river model RIVTOX.

Assumption (1) is a common approach for the watershed radionuclide wash off modeling (Monte, 1996). Assumption (2) leads to an overestimation of the radionuclide lateral peak inflow to the river net. However by this way JRETRACE provides an upper conservative estimate of the radionuclide wash off from the watersheds to the river net acceptable for the JHDM taking into account the simplicity of the input data for this type of model.

The input data for J-RETRACE are:

- Grid of the fallout density generated by the Atmospheric Dispersion Module (ADM/LSMC) of JRODOS, or in the stand-alone version of JHDM - by the model "Rimpuff" (Ievdin et al., 2010);

- River network shape presented in ESRI Shape format (*.shp);

- Computational points of J-RIVTOX model in ESRI Shape format (*.shp) which are located on this network;

- "Buffer" around river network (radius is 50km) which represent the watershed area of wash-off;

- Time series of the precipitation rate at the nodes of the fallout grid interpolation from the grid of the regional Numerical Weather Prediction model that are used in JRODOS for the ADM. 
In accordance with the above assumptions (1) and (2) for each watershed cell $(i, j)$ of the fallout grid located in the "buffer" zone, the rate of the lateral inflow $M_{i j}$ $(\mathrm{Bq} / \mathrm{sec})$ of the radionuclide wash off to the nearest node of the river computational grid of RIVTOX is calculated for each time interval as:

$$
M_{i j}=K^{w} \cdot D_{i j} \cdot S \cdot R_{i j}
$$

where $K^{w}$ is the time depending wash-off coefficient (m-1) calculated using simple empirical formulas (Monte, 1996), $D_{\mathrm{ij}}\left(\mathrm{Bq} / \mathrm{m}^{2}\right)$ is the density of the radionuclide contamination per cell of the computational grid obtained from the ADM, $S\left(\mathrm{~m}^{2}\right)$ is the area of the computational cell, $R_{i j}(\mathrm{~m} / \mathrm{s})$ is the precipitation rate in the computational cell. In each computational node of the J-RIVTOX model the lateral inflow is calculated as a sum of the $M_{i j}$ values from the cells that are automatically identified as connected to this node.

\subsection{J-RIVTOX - model of radionuclide transport in river network}

The J-RIVTOX module includes the sub-models and assumptions:

- a hydraulics model describing the water propagation in a river network on the basis of a finite-difference solution of the Saint Venant equations with a diffusive wave approximation;

- a sediment transport model simulating suspended sediments and erosiondeposition processes in the river channel on the basis of a finite-difference solution of the advection-diffusion equations, where the "source-sink" term is defined by semi-empirical formulas for the equilibrium sediment concentrations;

- a radionuclide transport model being based on a numerical solution of the advection-diffusion equation describing radionuclide transport in the river flow.

Typical input data are:

- river network shapes (ESRI Shape format), which are used for the construction of computational grids along the river branches. The river grid nodes are then connected with the fallout cells of the J-RETRACE model;

- data about the discharges in the water gauge stations of the river network used for the calibration purposes;

- basic data concerning river width and river depth for each tributary of the considered river network;

- forecasts of the water discharges at the input cross-sections of the considered river network for the simulation period.

The simplified formulas used in J-RIVTOX together with the empirical coefficients derived from the above mentioned data for the dependency of the area 
of the cross-section in relation to the water level, allow to reduce considerably the effort in collecting detailed information on the profiles the river cross-sections.

\subsection{J-FDM(A) - foodchain and dose module, aquatic}

The task of the RODOS aquatic foodchain and dose module FDMA (Gering et al., 2003) is to simulate the transfer of radionuclides in the foodchain due to contamination of water (used for drinking, animal feeding, irrigation of crops), and for the assessment of doses from aquatic pathways to the population (internal exposure via ingestion of drinking water, agricultural products, and fish). Individual as well as collective doses are calculated. New FORTRAN codes have been created on the basis of the FDMA formulas to be used in the J-FDMA module. For simplicity the atmospheric fallout/ deposition on the irrigated territories was not included because usually the areas from aquatic exposure in a river basin are much larger in size than the areas of the fallout region.

The endpoints of FDMA are the time dependent activity concentrations in a variety of feed and foodstuffs and the resulting radiation exposure for the population via the exposure pathways:

- consumption of foodstuffs contaminated by animal feeding water or irrigation; - consumption of contaminated drinking water and fish.

The following input data required by J-FDMA should be predefined for the area of interest:

- borders of the radioecological regions;

- number of inhabitants;

- amount of foodstuff production;

- $\quad$ soil type category.

The model parameters describing the food chain transfer and radiation exposure are kept in a model data base. The default values of these parameters, derived for mid-European conditions, can be used for any implementation. However for more detailed studies a customization might be appropriate.

\section{JHDM software: architecture and interfaces}

The JHDM module is developed as a set of models integrated into JRODOS (Ievdin et al., 2010) using its databases, Java tools for User Interface (UI) and data management. The geographical information is processed and visualized by the GIS subsystem of JRODOS, developed on the basis of the open source Geotools library. Model runs are organized as tasks that contain model metadata and all information related to that particular run: input, output data, messages, warnings 


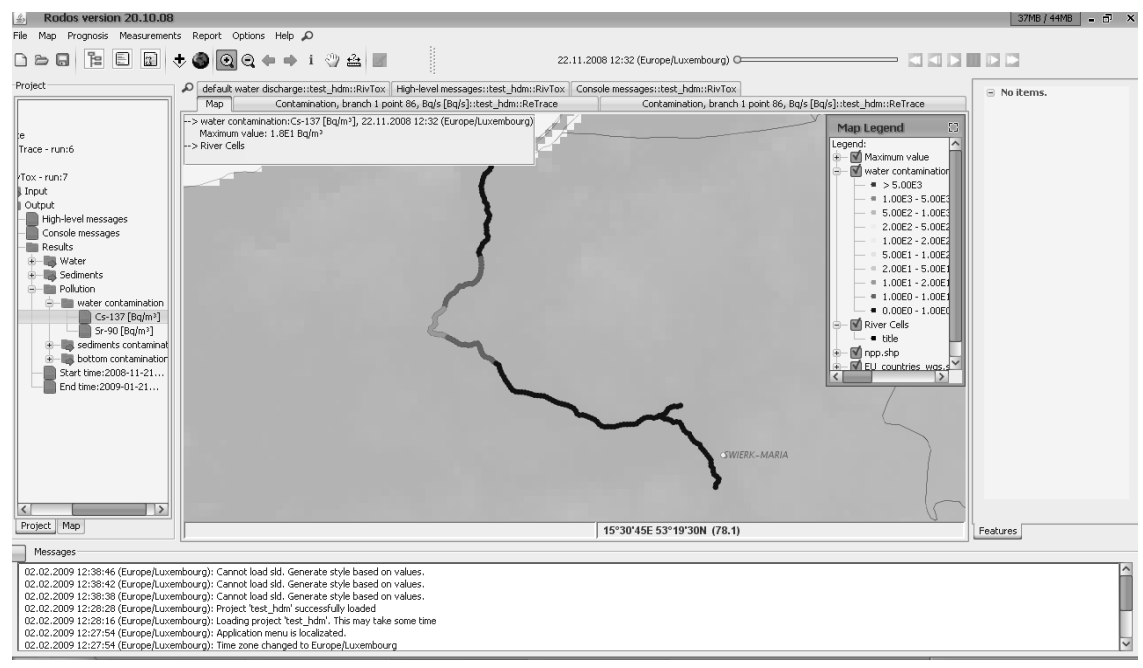

Figure 1 - Main User Interface of the JRODOS with the map of the Vistula river network starting at Swierk. Cs ${ }^{137}$ concentration is solute calculated by J-RIVTOX for some moment after the release in the Vistula River is shown by different colors.

and errors occurred during a model run. The tasks are combined into projects based on model chains. Management of the projects includes the following activities: creating, storing in and loading from database, reusing as template to build other project, sharing with other users and finally deleting the project by the owner or system administrator.

The UI of JRODOS has several distinct parts. The main window of JRODOS consists of the main menu, the toolbar, the project explorer/map and explorer window, the message window, the property/report window, the input window, and finally the map window, where results of the calculations can be displayed. The UI can be customized for specific river basin of interest (Fig. 1).

The following results are calculated and can be visualized in the UI:

- J-RETRACE: contamination from the watershed washed out to the branches of the considered river;

- J-RIVTOX: water data (discharge, velocity, area, width, depth), sediment data (concentration, reference data, depth), pollution data (radionuclide contamination of water, sediment and bottom layer);

- J-FDMA: concentration in the main food products, dose from irrigation, dose from fish, dose from water and total dose. 
The results can be presented in the main window using predefined color codes along the river for the selected time interval. Alternatively the same quantities can be visualized as time dependent plots at the selected nodes, as well as in the form of tables.

\section{JHDM implementation for the vistula river basin}

Tasks of implementation and input data

The Vistula river basin, Poland, has been selected for the JHDM implementation within EURANOS following the Danube Basin Demo to test the customization needs of a National Emergency Center in cooperation with a national Meteorological Service. In Poland JHDM has been installed and tested by:

- Radiation Emergency Centre (CEZAR) of the National Atomic Energy Agency and the Institute of Atomic Energy POLATOM (IAE), which acts as the Technical Support Organization of CEZAR (JHDM has been installed in both);

- Institute of Meteorology and Water Management (IMWM), Warsaw, which operates an Integrated Hydrological Monitoring and Forecasting System for the Vistula River Basin developed together with the Swedish Meteorological and Hydrological Institute.

The IMWM data has been used for J-RIVTOX model tuning and calibration.

The fallout from the research reactor of IAE at Swierk (close to Warsaw) was simulated by the LSMC module of JRODOS to produce the input data for JRETRACE. To simulate the transport of radionuclides from atmospheric deposition, downstream of the Swierk area, the following river network has been simulated (Fig. 1):

- The Vistula river from Gusin (location at river $\mathrm{km} \mathrm{461.5)} \mathrm{to} \mathrm{the} \mathrm{Baltic} \mathrm{Sea;}$

- The Narew river from Debe reservoir to the junction with the Vistula River.

The IMWM data for the high flood of 1988 has been used for the calibration of the model parameters. Comparison of the simulated and measured water discharges during the high flood in 1979 (Fig. 2) demonstrates that JRIVTOX, based only on the above described basic input parameters without detailed cross-section data and without discharges from all tributaries, can produce reasonable results for the flood routing in the Vistula river with respect to maximum discharges and travel time for the propagation of the peaks of the high flood. 

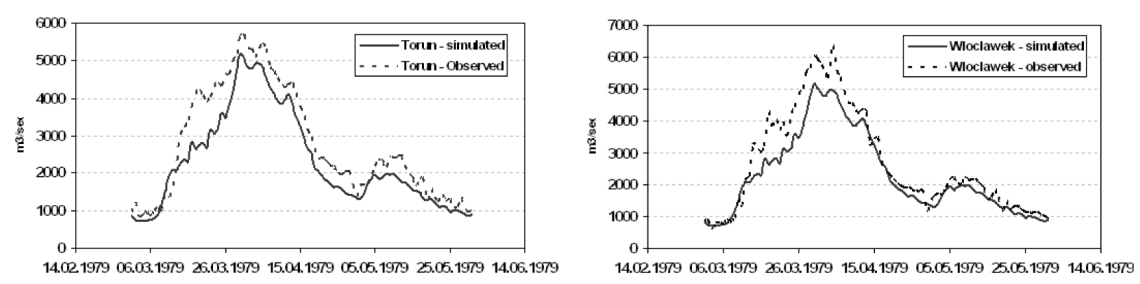

Figure 2 - Observed (dashed lines) hydrograph of high flood 1979 at two water gauge stations in the Vistula River in comparison with the discharges simulated by J-RIVTOX (solid lines).

\subsection{Users feedback}

JHDM has been tested by the Users in CEZAR and IAE for a fictional release from the IAE, Swierk. Two standard short-range modules (ATSTEP: ALSMC and RIMPUFF: RLSMC) were used to create initial conditions for J-RETRACE, however only one (ALSMC) was used for initialization of the HDM subsystem as no essential difference was noticed between the two ADMs. The dynamics of the radioactive contamination along the Vistula river, the contamination of river biota and the doses via aquatic pathways to the population in coastal areas have been simulated. The examples of the simulation are presented in Figure 3.

One of the main conclusions from the exercise was that all JHDM results can be very helpful in supporting the decision making team. In particular the following results of the simulation models are of interest:

- RETRACE: contamination from the branches of the considered river;

- RIVTOX: water data (discharge, velocity, area, width, depth), sediment data (concentration, reference data, depth), pollution data (contamination of water, sediment and bottom layer);

- FDMA: concentration in main food products, dose from irrigation, dose from fish consumption, dose from drinking water and the total dose.

In particular likened points such as the estimation of the contamination of the river water at selected point as a function of time and doses to the public have been highly appreciated. It was recommended to continue the development of the system and combine dose calculations of FDMA with the doses calculated via nonaquatic pathways by other modules of JRODOS. Also the model development for the simulation of the consequences of a direct point release of radioactive isotopes into the river water was recommended.

Recommendations related to the user interface have been realised within the project. A further recommendation was to allow the input of measured data and to 


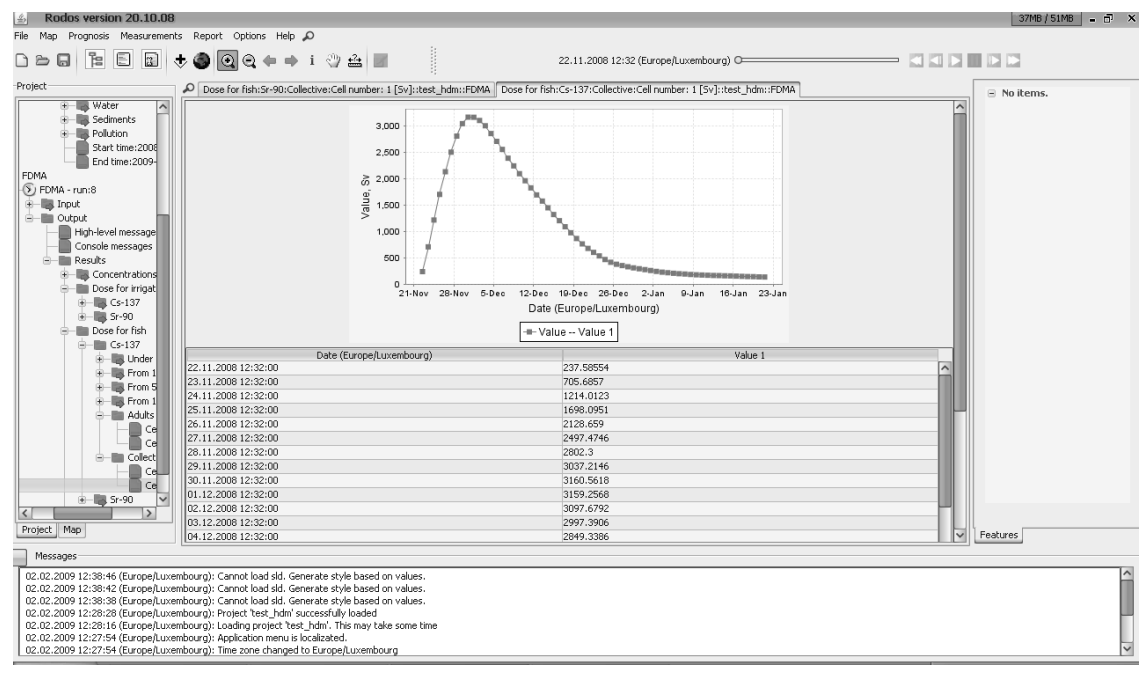

Figure 3 - Dose from $\mathrm{Cs}^{137}$ via fish consumption at selected point as a function of time (J-FDMA).

provide means for a graphical comparison of the observed value and the simulated results as a first step of the implementation of data assimilation procedures in JHDM.

\section{Conclusions}

A new version of the Hydrological Dispersion Module (JHDM) has been developed within the EURANOS project for the re-engineered decision support system RODOS (JRODOS). JHDM as module of JRODOS utilizes modern software technologies to clearly improve the system with respect to user friendliness and more easy tolls for the developer to integrate simulation models (new architecture, JAVA libraries, open source GIS libraries). To simplify the customization in national emergency response centers, JHDM was designed to include only simplified but adequate simulation models. This comprises models for the transport of radionuclides in a watershed, their movement from the watershed to the river water, their transport downstream in the river and finally the dose calculations. All models require only a very limited set of basic input parameters for the customization to the area of interest. The pilot implementation of JHDM to the Vistula River basin has received a positive feedback from the end users with the recommendations to fully integrate JHDM into JRODOS and further improve the corresponding models and interfaces. 


\section{REFERENCES}

Gering F., Hübner S., Müller H. (2003) User Guide for the Aquatic Food Chain and Dose Module FDMA in RODOS PV4.0, RODOS(WG3)-TN(99) 10, FZK Karlsruhe, 49 p.

Ievdin I., Trybushnyi D., Zheleznyak M., Raskob W. (2010) RODOS re-engineering: aims and implementation details, Radioprotection 45, S181-S189.

Johannessen O.M., Volkov V.A., Pettersson L.M., Maderich V.S., Zheleznyak M.J., Gao Y., Bobylev L.P., Stepanov A., Neelov V., Tishkov V.P., Nielsen S.P. (2009) Radioactivity and pollution in the Nordic Seas and Arctic Region: observations, modelling and simulations. Springer, Series: Springer Praxis Books, ISBN: 978-3-540-24232-1.

Kolomeev M., Madsen H. (2002) Description of RETRACE: A new catchment model of the hydrological dispersion module in the RODOS system RODOS(RA5)-TN(01)-09, Report of FP5 DAONEM Project FIKR-CT-2000-00025, FZK Karlsuhe. - 32 p.

Lepicard S., Heling R., Maderich V. (2004) POSEIDON/RODOS model for radiological assessment of marine environment after accidental releases: application to coastal areas of the Baltic, Black and North seas, J. Environ. Radioact. 72, 153-161.

Margvelashvily N., Maderich V., Zheleznyak M. (1997) THREETOX - a computer code to simulate three-dimensional dispersion of radionuclides in stratified water bodies, Radiat. Prot. Dosim. 73, 177-180.

Monte L. (1996) Analysis of models assessing the radionuclide migration from catchments to water bodies, Health Phys. 70, 227-237.

Monte L., Periañez R., Kivva S., Laptev G., Angeli G., Barros H., Zheleznyak M. (2006) Assessment of state-of-the-art models for predicting the remobilisation of radionuclides following the flooding of heavily contaminated areas: the case of Pripyat River floodplain, J. Environ. Radioactiv. 88, 267-288.

Onishi Y., Voitsekhovich O., Zheleznyak M. (Eds.) (2006) Chernobyl-What Have We Learned? : The Successes and Failures to Mitigate Water Contamination Over 20 Years, Springer, ISBN: 9781-4020-5348-1.

Raskob W., Heling R., Zheleznyak M. (2004) Is there a need for hydrological modelling in Decision Support Systems for nuclear emergencies? Radiat. Prot. Dosim. 109, 111-114.

Zheleznyak M., Heling R., Raskob W. (2002) Hydrological dispersion module of the decision support system RODOS, Radioprotection 37 (C1), 683-688.

Zheleznyak M., Demchenko R., Khursin S., Kuzmenko Yu., Tkalich P., Vitjuk N. (1992) Mathematical modeling of radionuclide dispersion in the Pripyat-Dnieper aquatic system after the Chernobyl accident, Sci. Tot. Environ. 112, 89-114.

Zheleznyak M.J., Tkalich P.V., Lyashenko G.B., Marinets A.V. (1993) Aquatic dispersion model -first approaches to integration into the $\mathrm{E}$ decision support system based on post-Chernobyl experience, Radiat. Prot. Dosim. 50, 235-242. 